\title{
Adubação nitrogenada e potássica na severidade da antracnose em dois cultivares de milho
}

\author{
Diego de Oliveira Carvalho ${ }^{1}$, Edson Ampélio Pozza², Carlos Roberto Casela ${ }^{1}$, Rodrigo Véras da Costal, \\ Adélia Aziz Alexandre Pozza ${ }^{3}$ César Oliveira Carvalho
}

\begin{abstract}
RESUMO
O equilíbrio nutricional pode contribuir para a resistência das plantas às doenças. Com o objetivo de avaliar o efeito da interação entre as adubações nitrogenada e potássica na severidade das lesões da antracnose foliar e na nutrição mineral da cultura do milho, foram instalados dois experimentos, em casa de vegetação com dois cultivares, o DAS 2B710 (moderadamente resistente à doença) e o BRS 1010 (susceptível), cinco doses de N (75, 150, 300, 600 e 1200 mg $\mathrm{dm}^{-3}$ ) e cinco doses de $\mathrm{K} 63,125,250,500$ e $1000 \mathrm{mg} \mathrm{dm}^{-3}$ ). O delineamento experimental para cada cultivar foi em blocos inteiramente ao acaso, em esquema fatorial 5 x 5, com 25 tratamentos e quatro repetições. Cada vaso com quatro plantas constituiu uma parcela experimental. As doses de $\mathrm{N}$ e $\mathrm{K}$ foram divididas em quatro parcelas, com intervalos de dez dias a partir da semeadura, para os dois cultivares. Aos 21 dias após a semeadura, as plantas foram inoculadas e levadas para câmara úmida, com fotoperíodo de 16 horas, no escuro durante três dias consecutivos. Avaliou-se a severidade das lesões diariamente, até 11 dias após a inoculação. Aos 43 dias após a semeadura, a parte aérea das plantas foi colhida, secada e moída para determinar os teores de $\mathrm{N}$ e de $\mathrm{K}$. A quantidade de área foliar lesionada dependeu da interação entre os nutrientes. Em ambos os cultivares, os menores valores de severidade foram observados na menor dose de N, combinada com a maior dose de K. A severidade das lesões observada no cultivar moderadamente resistente foi $41 \%$ menor que a observada no cultivar susceptível. A adubação nitrogenada influenciou de forma negativa o teor de $\mathrm{K}$ da parte aérea.
\end{abstract}

Palavras-chave: nutrição mineral, doença, Colletotrichum graminicola, Zea mays.

\section{ABSTRACT \\ Nitrogen and potassium fertilization influence on anthracnose severity in two corn cultivars}

The nutritional balance may contribute to increase plant disease resistance. With the aim of evaluating the interaction of nitrogen and potassium fertilization on severity of leaf anthracnose and mineral nutrition of maize, two experiments were installed in a greenhouse using two cultivars of corn, DAS 2B710 (moderately resistant to disease) and BRS 1010 (susceptible). Five doses of $\mathrm{N}\left(75,150,300,600\right.$ and $\left.1200 \mathrm{mg} \mathrm{dm}^{-3}\right)$ and $\mathrm{K}\left(63,125,250,500\right.$ and $\left.1000 \mathrm{mg} \mathrm{dm}^{-3}\right) \mathrm{were}^{-}$ applied. The experimental design for each cultivar was completely randomized in a $5 \times 5$ factorial scheme, with 25 treatments and four replications. Each vase with four plants consisted of one experimental plot. The dosage of $\mathrm{N}$ and $\mathrm{K}$ were distributed in 4 applications at intervals of 10 days from sowing, for both cultivars. At 21 days after sowing, plants were inoculated and taken to a moist chamber with photoperiodic treatment of 16 hours in darkness for 3 consecutive days. After the inoculation, the severity was assessed daily for 11 days. At 43 days after sowing, the aerial

Recebido para publicação em 02/04/2012 e aprovado em 19/03/2013

${ }^{1}$ Engenheiros-Agrônomos, Doutores. Embrapa Milho e Sorgo, Rodovia MG 424, Km 65, 35701-970, Sete Lagoas, Minas Gerais, Brasil. diego@cnpms.embrapa. br; casela@cnpms.embrapa.br; veras@cnpms.embrapa.br

${ }^{2}$ Engenheiro-Agrônomo, Doutor. Departamento de Fitopatologia, Universidade Federal de Lavras, Caixa Postal 3037, 37200-000, Lavras, Minas Gerais, Brasil. edsonpozza@ gmail.com ${ }^{3}$ Engenheira-Agrônoma, Doutora. Instituto de Ciências Agrárias, Universidade Federal de Viçosa, Campus de Florestal, 35690-000, Florestal, Minas Gerais, Brasil. adelia.pozza @ ufv.br (autor para correspondência).

${ }^{4}$ Engenheiro-Agrônomo. Conselho de Ensino Pesquisa e Extensão, Universidade Federal de Viçosa, Campus de Viçosa, Avenida Peter Henry Rolfs, s/n, 36570-000, Viçosa, Minas Gerais, Brasil. cesar_bi@hotmail.com

Rev. Ceres, Viçosa, v. 60, n.3, p. 380-387, mai/jun, 2013 
part of the plant was harvested, dried and ground to determine the uptake of $\mathrm{N}$ and $\mathrm{K}$. The severity was significantly affected by the interaction between nutrients. In both cultivars, the lowest severity values were observed at the lowest dose of $\mathrm{N}$ combined with the higher dose of $\mathrm{K}$. The severity of the moderately resistant cultivar was $41 \%$ lower than in the susceptible cultivar. Nitrogen fertilization influenced negatively the K content in leaves and shoots.

Key words: mineral nutrition, disease, Colletotrichum graminicola, Zea mays.

\section{INTRODUÇÃO}

O milho (Zea mays L.), por seu potencial produtivo, composição química, valor nutritivo e multiplicidade de aplicações, seja na alimentação humana, seja na animal, firmou-se, ao longo da história, como um dos mais importantes cereais cultivados e consumidos, exercendo relevante papel socioeconômico e constituindo matéria-prima indispensável, capaz de impulsionar os mais diversificados complexos agroindustriais. Esse cereal destaca-se como uma das principais culturas do agronegócio brasileiro. O Brasil é o terceiro maior produtor mundial, atrás apenas dos Estados Unidos e da China, com produtividade média de $4.268 \mathrm{~kg} / \mathrm{ha}$, na safra 2010/11, a qual foi $3,3 \%$ menor do que a da safra de 2009/10 (CONAB, 2011).

$\mathrm{O}$ rendimento do milho pode ser influenciado por diversos fatores, dentre eles as doenças. Segundo Pinto et al. (2006), o aumento no plantio da safrinha, aliado à adoção do sistema de plantio direto, sem obedecer a um planejamento de rotação de culturas, contribuiu para aumentar também a incidência de doenças relatadas como de importância secundária para a cultura. Dentre as principais doenças, destaca-se a antracnose (Colletotrichum graminicola). Segundo White (1999), é uma doença muito importante nos Estados Unidos, na França, na Índia, nas Filipinas e em países da América do Sul. Ela pode reduzir o rendimento de grãos em até $40 \%$, dependendo do híbrido utilizado (Callaway et al., 1992).

Por ser necrotrófico, capaz de sobreviver em restos de cultura, C. graminicola ganhou importância entre os patógenos da cultura do milho, sobretudo nas áreas com sistema de plantio direto (Pinto et al., 2006). No Brasil, essa doença é um dos principais problemas da cultura do milho, ocorrendo em todas as principais regiões produtoras do país, seja em cultivos de safrinha, seja em plantios efetuados em períodos normais (Fancelli \& Dourado Neto, 2000).

Até o momento, nenhum produto químico foi registrado para o controle da antracnose. Nesse contexto, o Manejo Integrado de Doenças (MID) ganhou destaque, ao se preconizar o uso de estratégias de controle mais eficientes e seguras do ponto de vista ambiental. Segundo Pozza \& Pozza (2006), a nutrição mineral é um fator do ambiente capaz de ser manipulado com relativa facilidade, no MID. O estado nutricional das plantas pode determinar sua maior ou menor predisposição às doenças. A nutrição equilibrada promove maior capacidade de defesa das plantas. De acordo com Marschner (1995), a nutrição mineral pode influenciar o grau de resistência da planta, por modificar a morfologia ou a histologia, ou ainda alterar a composição química dos tecidos em resposta à infecção por patógenos. Além disso, o estado nutricional da planta interfere em seus mecanismos de defesa, principalmente contra doenças fúngicas, protegendo-as sob a forma de barreira física, evitando a penetração de hifas por meio do espessamento da cutícula e, ou, lignificação de células epidérmicas; por melhor controle da permeabilidade da membrana citoplasmática, impedindo assim a saída de açúcares e aminoácidos (dos quais os patógenos se nutrem) para o apoplasto ou para a superfície foliar, e por produzir compostos fenólicos com propriedades fungistáticas.

Vários trabalhos comprovaram que plantas submetidas a adubações não equilibradas, tornam-se mais susceptíveis às doenças (Pozza et al., 2001, Tanaka et al., 2002, Fidelis et al., 2003, Silveira \& Higashi, 2003; Garcia Júnior et al., 2003). Apesar das evidências do efeito do nitrogênio $(\mathrm{N})$ e do potássio $(\mathrm{K})$ no progresso de várias doenças em diversas culturas, são escassos os trabalhos a respeito da influência desses nutrientes na antracnose foliar do milho. Portanto, há necessidade de trabalhos para auxiliar o maior entendimento da relação nutrição-patógeno-hospedeiro no descrito patossistema e, consequentemente, contribuir com o MID, por meio da qualidade nutricional da cultura.

Diante do exposto, este trabalho teve como objetivo avaliar a influência da interação entre doses de nitrogênio e de potássio na intensidade da antracnose foliar em dois cultivares de milho.

\section{MATERIAL E MÉTODOS}

Foram implantados dois experimentos, em casa de vegetação, na área experimental do Centro Nacional de Pesquisa Milho e Sorgo, Embrapa Milho e Sorgo, no município de Sete Lagoas, MG. As coordenadas são latitude Sul de $19^{\circ} 28^{\prime}$, longitude Oeste de $44^{\circ} 15^{\prime} 08^{\prime \prime}$ e a altitude de

Rev. Ceres, Viçosa, v. 60, n.3, p. 380-387, mai/jun, 2013 
$732 \mathrm{~m}$. Os experimentos diferiram apenas em relação ao cultivar; os híbridos simples DAS 2B710 (moderadamente resistente à antracnose) e BRS 1010 (altamente susceptível à doença) foram avaliados no primeiro e no segundo experimentos (Silva, 2006; Carvalho et al., 2011).

O delineamento experimental, para os dois experimentos, foi em blocos inteiramente ao acaso, com 25 tratamentos e quatro repetições. Utilizaram-se vasos de plástico com dimensões de $23 \times 23 \times 18 \mathrm{~cm}$ e capacidade para 5 $\mathrm{kg}$ de solo. Cada vaso com quatro plantas constituiu uma parcela experimental. Os 25 tratamentos foram delineados em fatorial 5 x 5, isto é, cinco doses de $\mathrm{N}(75,150,300,600$ e $1200 \mathrm{mg} \mathrm{dm}^{-3}$ ) combinadas com cinco doses de K (63, $125,250,500$ e $1000 \mathrm{mg} \mathrm{dm}^{-3}$ ). Foi preparada solução estoque para cada um dos tratamentos, utilizando-se, como fontes de $\mathrm{N}$ e de $\mathrm{K}$, nitrato de potássio $\left(\mathrm{KNO}_{3}\right)$, nitrato de amônio $\left(\mathrm{NH}_{4} \mathrm{NO}_{3}\right)$ e cloreto de potássio $(\mathrm{KCl})$.

Em ambos os experimentos, foram utilizadas amostras do horizonte B de um Latossolo Vermelho distrófico, textura argilosa. Todos os vasos, contendo $5 \mathrm{~kg}$ dessa amostra de solo, foram umedecidos e incubados com $2 \mathrm{~g} \mathrm{~kg}^{-1} \mathrm{de}$ calcário dolomítico (PRNT 90,94\%), por três meses, visando a atingir a saturação por bases de $50 \%$ conforme recomendação para milho da CFSEMG (1999). A seguir, adicionaram-se superfosfato simples $\left(4 \mathrm{~g} \mathrm{~kg}^{-1}\right.$ de solo) e sulfato de magnésio $\left(0,310 \mathrm{~g} \mathrm{~kg}^{-1}\right.$ de solo). Os micronutrientes foram fornecidos por meio de solução, contendo ácido bórico $\left(4,6 \mathrm{mg} \mathrm{kg}^{-1}\right)$, sulfato de cobre $\left(6 \mathrm{mg} \mathrm{kg}^{-1}\right)$, sulfato de manganês $\left(10 \mathrm{mg} \mathrm{kg}^{-1}\right)$, molibdato de amônio (0,3 $\left.\mathrm{mg} \mathrm{kg}^{-1}\right)$ e sulfato de zinco $\left(22 \mathrm{mg} \mathrm{kg}^{-1}\right)$, no plantio, conforme recomendação de CFSEMG (1999). Para fornecer os nutrientes $\mathrm{N}$ e K, em cada tratamento, as aplicações foram parceladas em quatro vezes, em intervalos regulares de dez dias, a partir da data da semeadura.

Aos 21 dias após o plantio, marcou-se com tinta a porção central do limbo da $1^{\mathrm{a}}, 2^{\mathrm{a}}$ e $3^{\mathrm{a}}$ folhas, contadas a partir da folha mais jovem, naquela ocasião, e pulverizouse a parte aérea com suspensão de $10^{6}$ conídios de $C$. graminicola/mL de solução. Para propiciar condições favoráveis à infecção, as plantas inoculadas foram dispostas em câmara úmida e escura, por 16 horas, durante a noite, por três dias consecutivos. Após este período, as plantas foram dispostas em bancadas dentro da casa de vegetação, onde permaneceram por todo o período de avaliação.

Para avaliar a severidade da doença, utilizou-se escala de notas modificada, de Nicholson \& Warren (1976), com valores de 1 a 5 para representar a percentagem de área foliar lesionada (AFL) (Tabela 1). Com base no tipo da lesão e na estimativa da área foliar lesionada, as notas 1, 2 e 3 foram consideradas reação de resistência e as notas 4 e 5, de reação de susceptibilidade. Foram realizadas avaliações diárias durante 11 dias após a inoculação. As notas de severidade da última avaliação, aos 11 dias após a inoculação, foram convertidas em valores percentuais de área foliar lesionada.

Após o término das avaliações de severidade (aos 43 dias após o plantio), as partes aéreas das plantas de milho dos dois experimentos foram colhidas, lavadas e acondicionadas separadamente em sacos de papel. Para determinar o peso da matéria seca da parte aérea das plantas de milho, as amostras permaneceram em estufa, à temperatura de $65^{\circ} \mathrm{C}$, até peso constante, quando, então, promoveu-se sua moagem e o posterior encaminhamento para análise do teor de $\mathrm{N}$ e de $\mathrm{K}$, no Laboratório de Análise Foliar da Embrapa Milho e Sorgo. Amostras da matéria seca foram submetidas à digestão sulfúrica e nitroperclórica e os extratos foram utilizados na determinação de $\mathrm{N}$, pelo método de Kjeldahl, e de K, por fotometria de chama, respectivamente, segundo Silva (1999).

Os dados obtidos foram submetidos a análises de variância no programa SISVAR ${ }^{\circledR}$ - versão 4.6 (Build 6.1). Os dois experimentos foram submetidos à análise conjunta de dados ao longo do tempo. As variáveis significativas no teste $\mathrm{F}$ foram submetidas ao ajuste de modelos de regressão polinomial. Em seguida, foram plotadas as curvas. Quando houve interação significativa entre os nutrientes, plotaram-se as superfícies de resposta, com seus respectivos cortes.

\section{RESULTADOS E DISCUSSÃO}

A área foliar lesionada (AFL) da antracnose foi afetada, significativamente, a $1 \%$ de probabilidade, pela

Tabela 1. Escala de notas, proposta por Nicholson \& Warren (1976) modificada

\begin{tabular}{|c|c|c|}
\hline $\begin{array}{l}\text { Notas de } \\
\text { severidade }\end{array}$ & Tipo de infecção & $\begin{array}{c}\text { Área foliar } \\
\text { lesionada }(\%)\end{array}$ \\
\hline 1,0 & Ausência de doença & $0 \%$ \\
\hline 1,1 a 2,0 & Infecção leve, presença de pequeno número de lesões alongadas sem esporulação & 0,5 a $5,0 \%$ \\
\hline 2,1 a 3,0 & $\begin{array}{l}\text { Infecção de leve a moderada, presença de lesões alongadas sem esporulação } \\
\text { ou de reação de hipersensibilidade }\end{array}$ & 6,5 a $20 \%$ \\
\hline 3,1 a 4,0 & Infecção severa com grande número de lesões esporulantes e com alguma coalescência & 22 a $40 \%$ \\
\hline 4,1 a 5,0 & Infecção muito severa, com lesões abundantes e coalescidas & 42 a $60 \%$ \\
\hline
\end{tabular}

Rev. Ceres, Viçosa, v. 60, n.3, p. 380-387, mai/jun, 2013 
interação entre os nutrientes $\mathrm{N}$ e K, em ambos os cultivares.

Para o cultivar moderadamente resistente, DAS 2B710, observa-se, na superfície de resposta (Figura 1), uma linha, ou declive, com as menores AFL's, ou seja, um ponto de equilíbrio, resultante da interação entre os nutrientes. Na menor dose de $\mathrm{N}\left(75 \mathrm{mg} \mathrm{dm}^{-3}\right)$, combinada com a menor dose de $\mathrm{K}$ (63 $\mathrm{mg} \mathrm{dm}^{-3}$ ) ocorreu a maior AFL (42,05\%). Na dose $300 \mathrm{mg} \mathrm{dm}^{-3}$ de N, observou-se comportamento aproximadamente constante em todas as doses de $\mathrm{K}$ e AFL média de 32,2\%. Na maior dose de $\mathrm{K}\left(1200 \mathrm{mg} \mathrm{dm}^{-3}\right)$, observou-se inversão da curva, houve maior AFL na menor dose de $\mathrm{N}$ ( $\left.63 \mathrm{mg} \mathrm{dm}^{-3}\right)$, até o ponto de mínimo com $\mathrm{N}$ igual a $571 \mathrm{mg} \mathrm{dm}^{-3}$, aumentando, a partir daí, até a maior dose de N (1000 mg dm ${ }^{-3}$ ). Ou seja, novamente, a interação entre doses foi evidente no comportamento da doença.

A redução da doença nas três doses, 63, 125 e $250 \mathrm{mg}$ $\mathrm{dm}^{-3}$, até o ponto de mínimo, foi de aproximadamente $59 \%$. A partir desse ponto de mínimo, com o aumento das doses de $\mathrm{N}$ houve novamente o aumento da área foliar lesionada, devido ao desequilíbrio entre os nutrientes. Na maior dose de K (1000 $\left.\mathrm{mg} \mathrm{dm}^{-3}\right)$, combinada com a menor de $\mathrm{N}\left(75 \mathrm{mg} \mathrm{dm}^{-3}\right)$, ocorreu a menor percentagem de AFL (18,83\%). A partir da menor dose de N, houve aumento da AFL até atingir o ponto de máximo (39,3\%), com $813 \mathrm{mg} \mathrm{dm}^{-3} \mathrm{de} \mathrm{N}$ e com a inversão do comportamento da curva, reduzindo-se a doença a partir daí, porém ainda em altos valores de AFL. Ou seja, o comportamento da doença está relacionado com a interação entre as doses dos nutrientes $\mathrm{N}$ e $\mathrm{K}$.

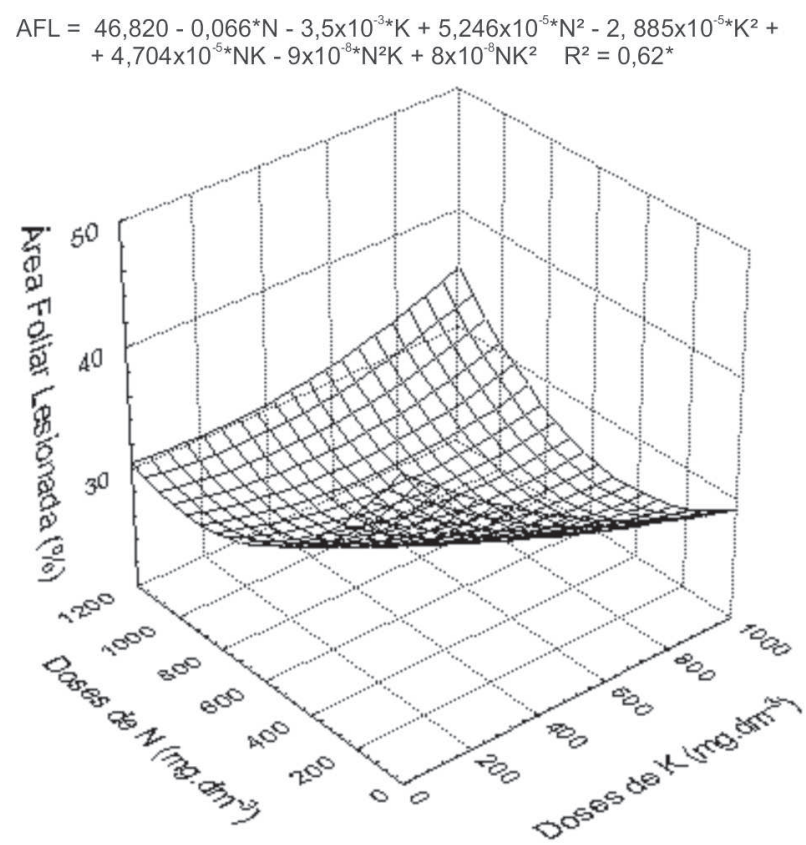

Figura 1. Percentagem de área foliar lesionada por antracnose (AFL) no cultivar DAS 2B710, em função de doses de $\mathrm{N}$ e de K no solo.
De acordo com Marschner (1995) e Pozza \& Pozza (2006), tanto macro, quanto micronutrientes, em doses não equilibradas, influenciam o vigor e a reação de defesa das plantas e podem contribuir para a mudança na susceptibilidade do hospedeiro às doenças. Outros trabalhos também constataram a importância do equilíbrio nutricional para o controle das doenças de plantas. Em estudo sobre o efeito de doses de $\mathrm{N}\left(0,60\right.$ e $\left.120 \mathrm{~kg} \mathrm{ha}^{-1}\right)$ e de $\mathrm{K}\left(0,25,50\right.$ e $\left.150 \mathrm{~kg} \mathrm{ha}^{-1}\right)$ na intensidade da cercosporiose (Cercospora zeae-maydis) do milho, em genótipos susceptíveis, na África do Sul, Caldwell et al. (2002) observaram aumento da severidade da doença com o incremento das doses de $\mathrm{N}$ e de $\mathrm{K}$ no solo. Esses autores concluíram que essa doença é mais severa em plantas com elevada exigência nutricional. Neste trabalho, observou-se maior exigência nutricional em K, para aumento da resistência das plantas à antracnose, se comparado à exigência do $\mathrm{N}$. Por outro lado, ao estudarem o efeito de doses de $\mathrm{K}\left(1,3,5\right.$ e $\left.7 \mathrm{mmol} \mathrm{L}^{-1}\right)$ e de $\mathrm{Ca}(2,4,6$ e $8 \mathrm{mmol} \mathrm{L}^{-1}$ ) na intensidade da cercosporiose (Cercospora coffeicola), em mudas de cafeeiro, em solução nutritiva, Garcia Júnior et al. (2003) também observaram a interação entre nutrientes. Observaram redução nas áreas abaixo da curva de progresso da incidência (AACPI) da cercosporiose do cafeeiro, até o ponto de mínimo, na dose $4 \mathrm{mmol} \mathrm{L}^{-1}$ de $\mathrm{K}$ e do total de lesões (AACPTL) até a dose 4,79 $\mathrm{mmol} \mathrm{L}^{-1}$ de $\mathrm{K}$. O suprimento de Ca promoveu efeito linear decrescente para a AACPI. Os autores creditaram essa redução na doença à competição entre os íons Ca e K pelos sítios de absorção; também relataram a influência da interação e a importância do equilíbrio nutricional nesse patossistema.

Com relação ao cultivar susceptível (BRS 1010), embora tenha ocorrido diferença significativa no teste F para a interação N x K, os testes " $t$ " para a estimativa dos parâmetros não indicaram diferenças significativas, tanto para o modelo linear da reta, quanto para o quadrático, refletindo a pouca variação ocorrida neste genótipo, em função da nutrição mineral com $\mathrm{N}$ e K. A amplitude do efeito foi pequena, embora os valores de menor e maior percentagem tenham sido observados nos mesmos tratamentos do cultivar DAS 2B710. Isto é, a menor AFL (48\%) também foi observada no tratamento com a combinação de $75 \mathrm{mg} \mathrm{dm}^{-3}$ de $\mathrm{Ne} 1000 \mathrm{mg} \mathrm{dm}^{-3}$ de $\mathrm{K}$ e a maior (60\%), com as doses de $75 \mathrm{mg} \mathrm{dm}^{-3}$ de $\mathrm{N}$ e $63 \mathrm{mg} \mathrm{dm}^{-3}$ de K. A amplitude de diferença entre a maior e a menor percentagem de AFL, no cultivar susceptível (BRS 1010), foi de $20 \%$, enquanto, para o cultivar moderadamente resistente (DAS 2B710), foi de 54\%. Sendo assim, no cultivar moderadamente resistente o efeito dos nutrientes $\mathrm{N}$ e $\mathrm{K}$ no controle da doença foi $34 \%$ maior do que no cultivar susceptível. Pozza et al. (2004) também verificaram o efeito do Si no controle da cercosporiose do cafeeiro, no cultivar 
moderadamente resistente Catuaí, diferindo do cultivar resistente Icatu. O suprimento de $\mathrm{Si}$ promoveu a formação de cera na cutícula, tornando a superfície foliar hidrofóbica, reduzindo a ocorrência da doença no cultivar moderadamente resistente à cercosporiose, e não teve efeito no cultivar resistente. Essas observações corroboraram as de Marschner (1995) sobre o efeito da nutrição no controle de doença ser relativamente pequeno, em cultivares com elevada resistência ou susceptibilidade, porém maior, em cultivares moderadamente susceptíveis ou parcialmente resistentes, principalmente se houver aumento de genes de resistência horizontal, que contribuam na formação de barreiras químicas ou físicas contra os patógenos.

Os resultados obtidos confirmaram as diferenças expressivas na resistência à antracnose foliar entre os cultivares DAS 2B710 (moderadamente resistente) e BRS 1010 (altamente susceptível). Ao contrário do cultivar DAS
2B710, independentemente das doses de N e de K utilizadas, a severidade da antracnose em plantas de BRS 1010, a partir da segunda avaliação, foi sempre elevada, ou seja, a adubação com $\mathrm{N}$ e com K não interferiu, de forma significativa, na resposta desse cultivar à doença, nesse experimento. Além disso, a severidade da antracnose foliar nesse material foi sempre superior àquela observada em DAS 2B710, atingindo valores próximos ou iguais ao máximo na escala de notas. Em média, a AFL de DAS 2B710 foi $41 \%$ menor que aquela observada em BRS 1010, com valores extremos que variaram entre 25 e $61 \%$ (Figura 1). Vaz-de-Melo et al. (2010) também observaram a independência da adubação nitrogenada nas reações de alguns híbridos experimentais de milho, em relação à mancha de Curvulária. Por essa razão, o uso da adubação equilibrada em $\mathrm{N}$ e K, como medida de manejo da antracnose foliar do milho, é dependente do genótipo estudado com o qual se está trabalhando.

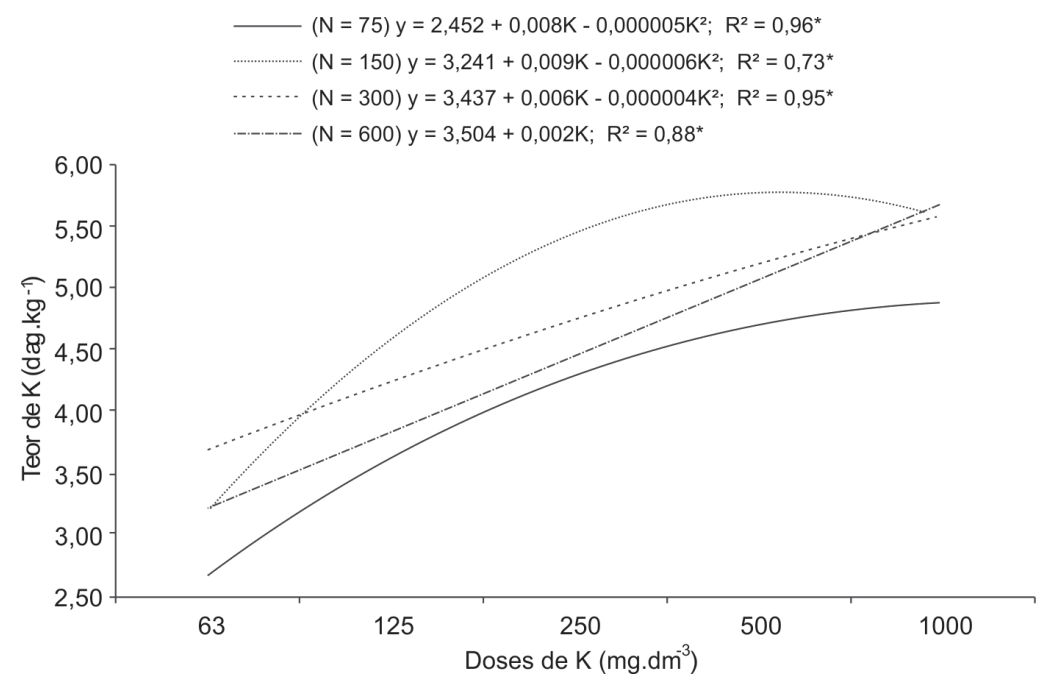

Figura 2. Teor de K na parte aérea do cultivar DAS 2B710, em função de doses de K em cada dose de N no solo.

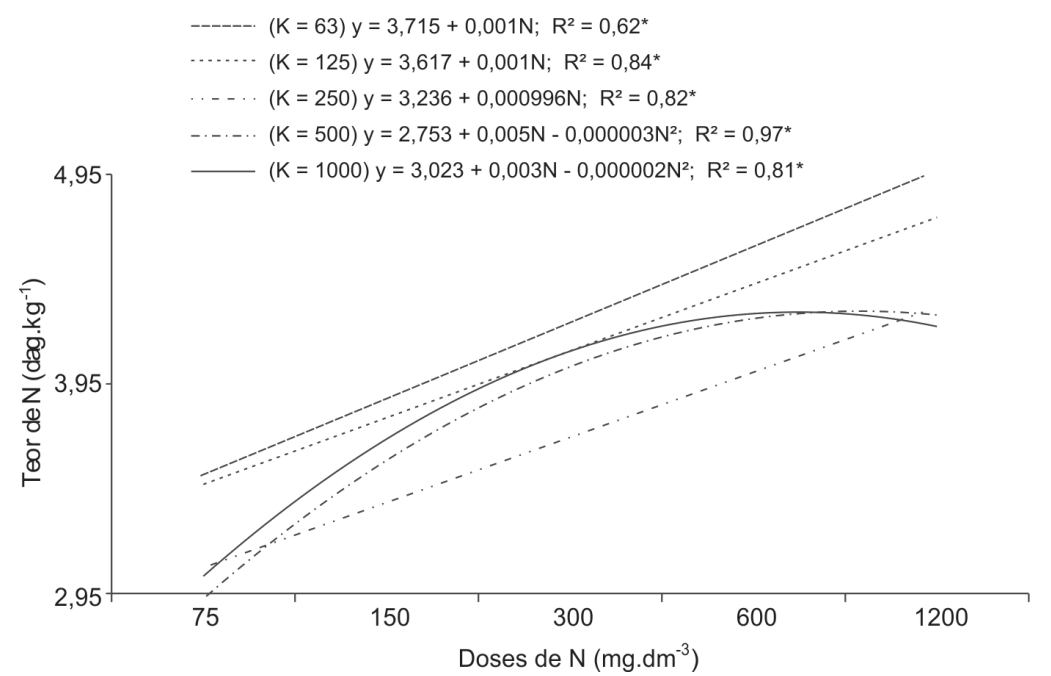

Figura 3. Teor de N na parte aérea do cultivar BRS 1010, em função de doses de $\mathrm{N}$ em cada dose de K no solo. 


\section{Nutrição}

Em ambos os cultivares, houve aumento dos teores de $\mathrm{N}$ e de $\mathrm{K}$ na parte aérea das plantas, com o incremento das doses de $\mathrm{N}$ e de $\mathrm{K}$ no solo (Figuras 2 e 3, respectivamente). Isto é, com o aumento do fornecimento dos nutrientes no solo, houve maior absorção pelas plantas. Pinheiro et al. (2011), avaliando a influência de doses de K $\left(0,150,300,450\right.$ e $\left.600 \mathrm{mg} \mathrm{dm}^{-3}\right)$ e de $\mathrm{Ca}(0,75,150,225$ e 300 $\mathrm{mg} \mathrm{dm}{ }^{-3}$ ), na reprodução do nematoide do cisto da soja (Heterodera glycines), também relataram aumento do teor de $\mathrm{K}$ com incremento das doses desse nutriente no solo.

Além disso, observou-se também a redução nos teores de $\mathrm{K}$ na parte aérea, com o incremento das doses de $\mathrm{N}$ no solo, em ambos os cultivares (Figura 4A e B). Esse fato indica a ocorrência de competição entre os cátions $\mathrm{NH}_{4}^{+} \mathrm{e}$
$\mathrm{K}^{+}$pelos sítios de absorção nas raízes (Malavolta, 2006). $\mathrm{O}$ aumento das doses de $\mathrm{N}$ influenciou nos teores de $\mathrm{K}$ na parte aérea somente nas doses 500 e $1000 \mathrm{mg} \mathrm{dm}^{-3}$ de K (Figura 4A). Pozza et al. (2001) também relataram redução nos teores de $\mathrm{K}$ nas folhas de mudas de cafeeiro, em solução nutritiva, com o aumento das doses de $\mathrm{N}$ de 3 para 15 mmol L ${ }^{-1}$. Além desses autores, Garcia Júnior et al. (2003) relataram a ocorrência dessa competição entre os cátions $\mathrm{Ca}^{2+} \mathrm{e} \mathrm{K}$, fato também observado neste experimento (Figura 5). Os teores de Ca na parte aérea do milho reduziram-se, com o aumento das doses de $\mathrm{K}$ adicionadas ao solo, para todas as doses de N. Segundo Epstein (1972), a limitação na quantidade de um elemento favorece a absorção do outro íon de mesma carga, ou a diminuição da absorção dos íons de carga oposta.

A
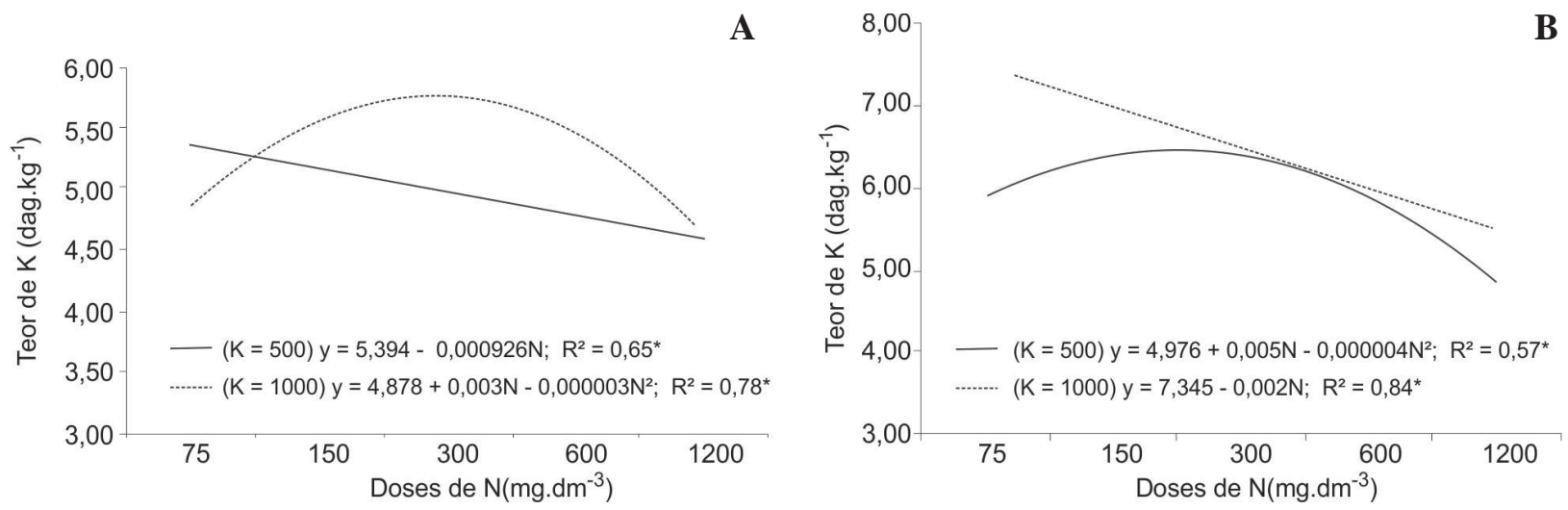

Figura 4. A) Teor de K na parte aérea do cultivar DAS 2B710 e B) do cultivar BRS 1010, em função de doses de N em cada dose de K no solo.

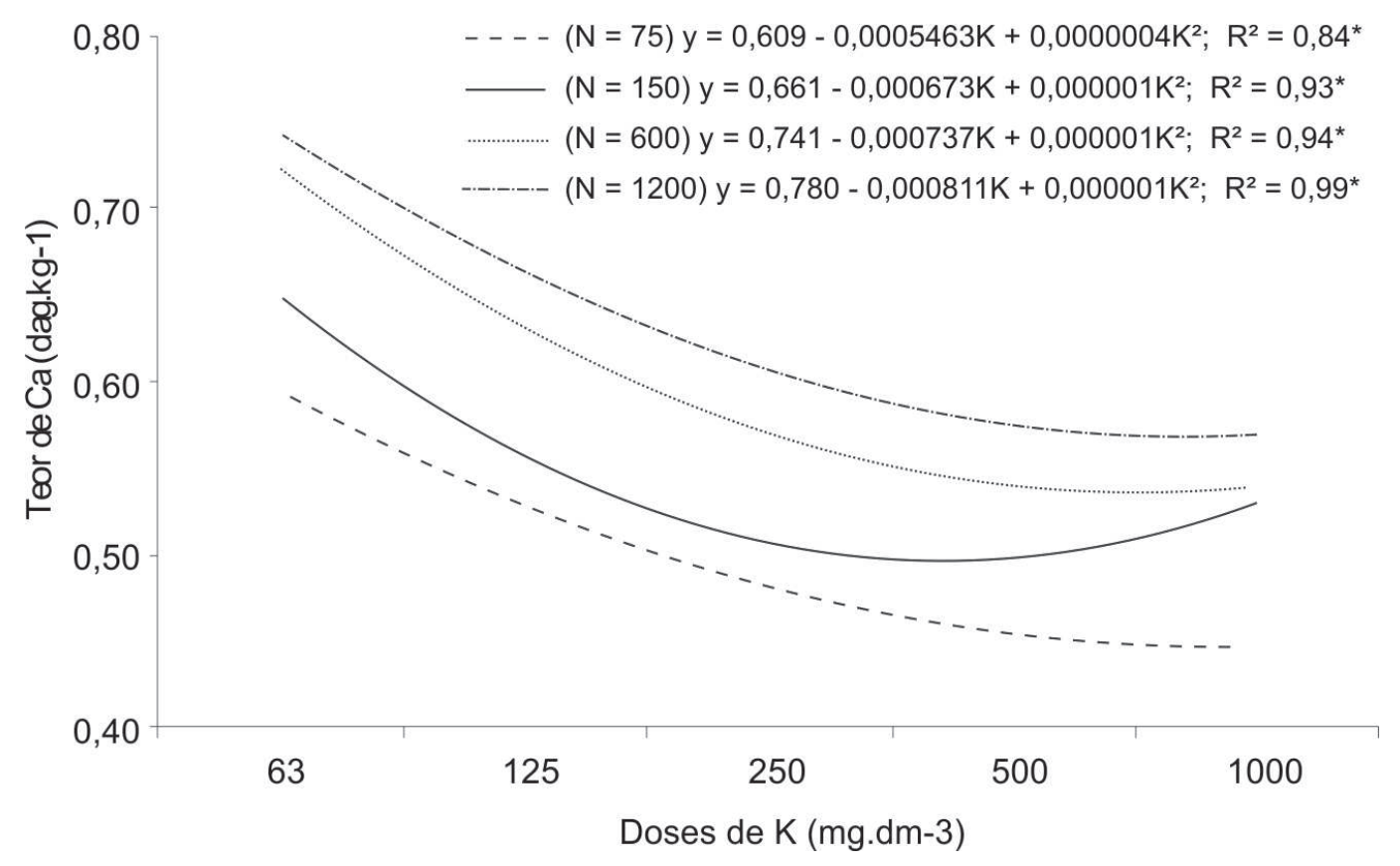

Figura 5. Teor de Ca na parte aérea do cultivar BRS 1010, em função de doses de N em cada dose de K no solo. 
Os teores limites de $\mathrm{N}$, obtidos na parte aérea das plantas, variaram de 2,3 a 3,8 dag kg-1 (DAS 2B710) e de 3,0 a 4,9 dag kg-1 (BRS 1010). Em ambos os cultivares, esses teores diferiram, tanto para menos (DAS 2B710), quanto para mais (BRS 1010), daqueles sugeridos pela CFSEMG (1999) como referência (2,7 a 3,2 dag kg-1).

Os teores limites de $\mathrm{K}$ na parte aérea das plantas variaram de 4,2 a 5,6 dag kg-1 (DAS 2B710) e de 3,1 a 4,3 dag kg${ }^{1}$ (BRS 1010). Em ambos os cultivares, esses teores apresentaram-se bem acima dos valores de referência (1,7 a 2,3 dag $\mathrm{kg}^{-1}$ ) sugeridos pela CFSEMG (1999), indicando provável consumo de luxo desse nutriente, pois o seu incremento não promoveu aumento de MSPA (Figuras 6A e B). Esses teores excessivos de K na parte aérea podem ter influenciado na produção de matéria seca. A MSPA reduziu-se, com o aumento do suprimento de $\mathrm{K}$, para todas as doses de $\mathrm{N}$, exceto na dose $1200 \mathrm{mg} \mathrm{dm}^{-3}$ de $\mathrm{N}$. Essa dose de $\mathrm{N}$ também foi elevada, permitindo a adaptação da planta a níveis elevados de $\mathrm{N}$ e de $\mathrm{K}$, entrando em equilíbrio, em alto status nutricional, e não mais se reduzindo a MSPA.
$\mathrm{MSPA}_{\mathrm{DAS}}=10,419+2,377 \times 10^{-4} \mathrm{~N}-0,003 \mathrm{~K}-1,9 \times 10^{-7} \mathrm{~N}^{2}+4,5 \times 10^{-7} \mathrm{~K}^{2}+$ $+2,3 \times 10^{-6} \mathrm{NK}, \quad \mathrm{R}^{2}=0,47^{*}$

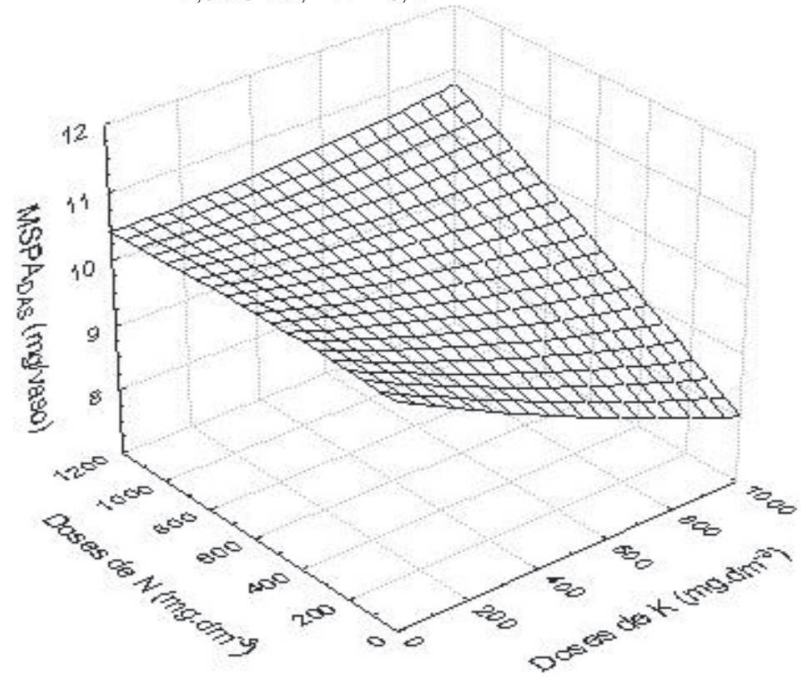

$\mathrm{MSPA}_{\mathrm{BRS}}=9,584-0,001 \mathrm{~N}-0,004 \mathrm{~K}+1,361 \times 10^{-6} \mathrm{~N}^{2}+1,629 \times 10^{-6} \mathrm{~K}^{2}+$ $+1,588 \times 10^{-6} \mathrm{NK}, R^{2}=0,61^{*}$

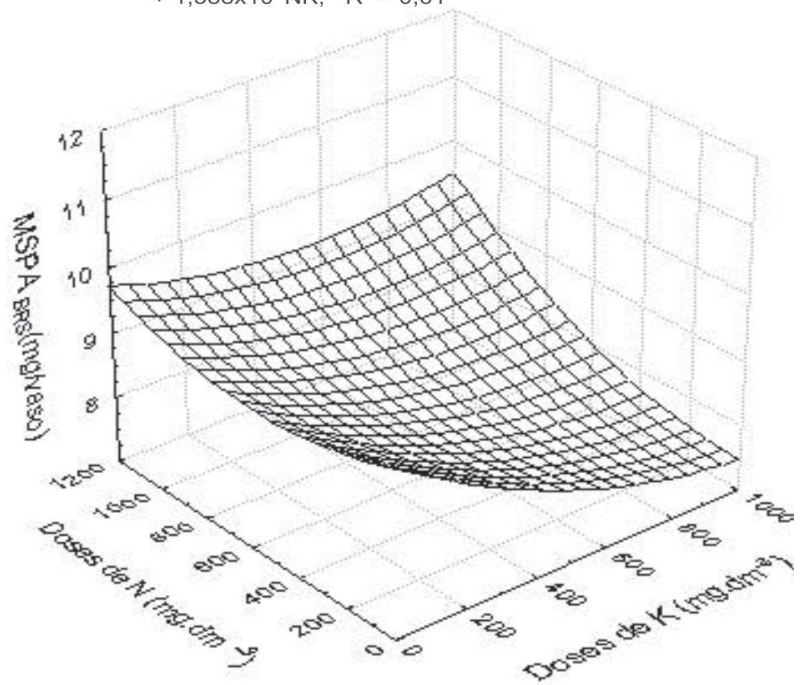

Figura 6. A) Matéria seca da parte aérea no cultivar DAS 2B710 e B) no cultivar BRS 1010, em função de doses de K e de N no solo.

\section{CONCLUSÕES}

A quantidade de área foliar lesionada (AFL) pela antracnose depende da interação entre os nutrientes $\mathrm{N}$ e K.

A resposta à interação nutricional, quanto à maior amplitude na AFL, foi constatada para o cultivar , moderadamente resistente, DAS 2B710.

Em ambos os cultivares, a maior AFL foi obtida no tratamento com as menores doses de $\mathrm{N}$ e de $\mathrm{K}(75 \mathrm{mg}$ $\mathrm{dm}^{-3}$ de $\mathrm{N}$ e $63 \mathrm{mg} \mathrm{dm}^{-3}$ de $\mathrm{K}$, respectivamente), e, a menor AFL, no tratamento com a dose $75 \mathrm{mg} \mathrm{dm}^{-3}$ de N, combinada com $1000 \mathrm{mg} \mathrm{dm}^{-3}$ de $\mathrm{K}$. O aumento das doses de $\mathrm{N}_{-} \mathrm{NH}_{4}^{+}$reduziu o teor de $\mathrm{K}$ na parte aérea, para ambos os cultivares de milho.

A adubação equilibrada com $\mathrm{N}$ e K, como auxiliar no manejo da doença, é influenciada pela expressão do genótipo de milho, quanto à resistência ou susceptibilidade à antracnose foliar.

\section{REFERÊNCIAS}

Caldwell PM, Ward JMJ, Miles N \& Laing MD (2002) Assessment of the effects of fertilizer applications on gray leaf spot and yeld in maize. Plant Disease, 86:859-866.

Callaway MB, Smith ME \& Coffman WR (1992) Effect of anthracnose stalk rot on grain yield and related traits of maize adapted to the northeastern. Canadian Journal Plant Science, 72:1031-1036.

Carvalho DOC, Pozza EA, Casela CR \& Costa RV (2011) Efeito do nitrogênio e do potássio no período de incubação e no período latente de Colletotrichum graminicola em duas cultivares de milho. Disponível em: <http://www.alice.cnptia.embrapa.br/ bitstream/doc/491262/1/Efeitonitrogenio1.pdf.> Acessado em: 05 de agosto de 2011.

Comissão de Fertilidade do Solo do Estado de Minas Gerais - CFSEMG (1999) Recomendação para o uso de corretivos e fertilizantes em Minas Gerais: $5^{\text {a }}$ aproximação. Viçosa, UFV. 359p.

Companhia Nacional de Abastecimento - CONAB (2011) $5^{\circ}$ Levantamento - Safra Agrícola de Grãos 2010/2011. Disponível em: <http://www.conab.br> Acessado em: 18 de junho de 2011.

Epstein E (1972) Mineral nutrition of plants. New York, J. Wiley. $412 \mathrm{p}$. 
Fancelli AL \& Dourado Neto D (2000) Produção de milho. Guaíba, Agropecuária. 360p.

Fidelis RR, Miranda GV, Souza LV, Coimbra RR, Melo AV \& Galvão JCC (2003) Reação de cultivares de milho à mancha de Phaeosphaeria em estresse de nitrogênio. Bioscience Journal, 19:27-34.

Garcia Júnior D, Pozza EA, Pozza AAA, Souza PE, Carvalho JG \& Balieiro AC (2003) Incidência e severidade da cercosporiose do cafeeiro em função do suprimento de potássio e cálcio em solução nutritiva. Fitopatologia Brasileira, 28:286-291.

Malavolta E (2006) Manual de nutrição mineral de plantas. São Paulo, Agronômica Ceres. 638p.

Marschner H (1995) Mineral nutrition of higher plants. 2.Ed. New York, Academic. 889p.

Nicholson RL \& Warren HL (1976) Criteria for evaluation of resistance to maize anthracnose. Phytopathology, 66:86-90.

Pinheiro JB, Pozza EA, Pozza AAA, Moreira AS \& Alves MC (2011) Severidade da ferrugem da soja em função do suprimento de potássio e cálcio em solução nutritiva. Revista Ceres, 58:43-50.

Pinto NJA, Santos MA \& Wruck DSM (2006) Principais doenças da cultura do milho. Informe Agropecuário, 27:82-94.

Pozza AAA, Martinez HEP, Caixeta SL, Cardoso AA, Zambolim L \& Pozza EA (2001) Influência da nutrição mineral na intensidade da mancha-de-olho-pardo em mudas de cafeeiro. Pesquisa Agropecuária Brasileira, 36:53-60.

Pozza AAA, Alves E, Pozza EA, Carvalho JG, Montanari M, Guimarães PTG \& Santos DM (2004) Efeito do silício no con- trole da cercosporiose em três variedades de cafeeiro. Fitopatologia Brasileira, 29:185-188.

Pozza EA \& Pozza AAA (2006) A nutrição mineral no controle de doenças de plantas. In: Venzon M, Paula Júnior TJ \& Pallini A (Eds.) Tecnologias alternativas para o controle de pragas e doenças. Viçosa, EPAMIG. p.49-80.

Silva FC (1999) Manual das análises químicas de solos, plantas e fertilizantes. Brasília, Embrapa Solos-Embrapa Informática Agropecuária. 370p.

Silva VA (2006) Resposta de cultivares de milho a Colletotrichum graminicola. Dissertação de Mestrado. Universidade Estadual Paulista, Jaboticabal. 45p.

Silveira RLVA \& Higashi EN (2003) Aspectos nutricionais envolvidos na ocorrência de doenças com ênfase para o eucalipto. Piracicaba, IPEF-ESALQ/USP. p.1-13. (Circular Técnica, ${ }^{\circ}$ 200)

Tanaka MSA, Passos FA, Feitosa CT \& Tanaka RT (2002) Effect of mineral nutrition on manuring on anthracnose crown rot of strawberry caused by Colletotrichum fragarie. Summa Phytopathologica, 28:236-241.

Vaz-de-Melo A, Afférri FS, Dotto MA, Peluzio JM, Santos GR \& Carvalho EV (2010) Reação de híbridos de milho à Curvulária $s s p$ sob dois níveis de adubação com nitrogênio no sul do Tocantins. Scientia Agrária, 11:149-154.

White DG (1999) Compendium of corn diseases. 3.ed. St.Paul, American Phytopathological Society. 105p. 